DOI: $10.35355 / 0000045$

\title{
MARABAIXO: PATRIMÔNIO CULTURAL IMATERIAL DO AMAPÁ
}

\author{
Victor André Pinheiro Cantuário* \\ Universidade Federal do Amapá - UNIFAP \\ ve.cantuario@gmail.com
}

\begin{abstract}
RESUMO: O objetivo deste artigo é o de expor os aspectos característicos da cultura marabaixeira afroamapaense, destacando sua designação como Patrimônio Cultural Imaterial (PCI) inscrito na ordem das discussões culturais que se iniciaram na década de 1970 e se estenderam até o ano de 2006, quando ocorre a efetivação dos objetivos traçados na Convenção da UNESCO, que aconteceu em outubro de 2003, em Paris. Para isso, procedeu-se à consulta a textos impressos e outros provenientes de periódicos on-line os quais utilizam como categorias de análise termos que transitam pela formação de um recente campo de estudos, aquele da produção imaterial de cultura, portânto, fortemente popular e marcado por traços de oralidade. Os resultados obtidos com a escrita deste artigo demonstram que apesar de anúncio do Ministério da Cultura, em novembro de 2018, de ter sido tombado como PCI da região norte entre as Formas de Expressão, o Marabaixo ainda está por alcançar o reconhecimento social que lhe é devido.
\end{abstract}

PALAVRAS-CHAVE: Patrimônio cultural imaterial - Cultura afrodescendente - Marabaixo - História do Amapá - Política cultural.

\section{MARABAIXO: INTANGIBLE CULTURAL HERITAGE FROM AMAPA}

\begin{abstract}
This paper has by aim to expose the intrinsic aspects of the afro-amapaense marabaixeira culture, trying to focus on its designation as Intangible Cultural Heritage (ICH), listed in the cultural agenda of discussions which first began in the 1970's, going through the middle of the 2000's when has occurred the effectuation of the goals traced in the UNESCO Convention for the Safeguarding of the ICH, who took place in Paris, October 2003. In this way, it is eligible as methodology of academic written the reading of books and scientific articles available in on-line journals that are using as categories of analysis words or expression from the proper field of research such as intangible culture, therefore, strongly marked by the popular and oral aspects of social life. The results obtained with this paper show that despite the recent news from the Ministerio da Cultura that Marabaixo is now listed as ICH from Brazil North Region among the Forms of Expression, it has not yet reached the deserved social recognition.
\end{abstract}

KEYWORDS: Intangible cultural heritage - Afro-descendant culture - Marabaixo - History of Amapa Cultural policy.

Doutorando do Programa de Pós-graduação em Estudos Literários pela Universidade Estadual Paulista Júlio de Mesquita Filho (UNESP). Professor do Curso de Licenciatura em Pedagogia, Campus Santana, da Universidade Federal do Amapá (UNIFAP). 


\section{INTRODUÇÃO}

Discussões a respeito do que seja e de que modo é possível compreender o conceito de Patrimônio Cultural Imaterial (PCI) têm ocupado maior espaço nos círculos acadêmicos das ciências humanas e sociais de 2003 para cá em universidades e instituições de ensino superior tanto portuguesas quanto brasileiras.

Afirma-se isso pelo número de trabalhos produzidos em língua portuguesa nesse período. Alguns de relevância que podem ser citados são as dissertações de Cabral (2009), de Carvalho (2014) e as teses de Corá (2011) e Vieira (2007), as quais partem do documento resultante da Convenção da Organização das Nações Unidas para a Educação, a Ciência e a Cultura (UNESCO) de 2003, que estabeleceu as bases já em seu título para a Salvaguarda do Patrimônio Cultural Imaterial a fim de incluir em seu bojo todas as manifestações culturais que escapam da definição tradicional de objeto de cultura como algo essencialmente material, à maneira do que a cultura grega clássica entendia originalmente como resultado da poiésis. ${ }^{1}$

Outros trabalhos de destaque sobre o assunto são o livro do Instituto do Patrimônio Histórico e Artístico Nacional (IPHAN, 2010), a respeito das reflexões que o órgão apresenta, no período de 2003-2010, do documento da Unesco e o que se tem feito no país no tocante ao assunto, e o livro introdutório de Pelegrini e Funari (2008), para citar apenas alguns de além-mar e daqui.

Esse interesse, infere-se, teve crescimento a partir de eventos como a Convenção da Organização das Nações Unidas para a Unesco de 2003, mas está vinculado ao desenvolvimento de uma linguagem própria que vem se desenhando desde a segunda metade do século XX, cujo despontar se deve a uma série de ações postas em prática pela Organização das Nações Unidas como o documento escrito em 1972, na Convenção para a Proteção do Patrimônio Mundial, Cultural e Natural, o primeiro a discutir cultura imaterial, contudo, de maneira ainda imprecisa; as Recomendações para a Salvaguarda do Folclore e da Cultura Tradicionais, de 1989; a criação, em 1992, do

1 Ver: VÁZQUEZ, 2003. p. 28. O filósofo espanhol diferencia práxis de poiésis em seu sentido grego original, apresentando que a primeira deve ser percebida como qualquer ação que tenha fim em si mesma, enquanto a segunda é ação que produz ou fabrica algo, por isso sendo apropriado dizer que toda ação cultural é uma ação poética porque ultrapassa o agente que a produziu. 
Disponível em: www.revistafenix.pro.br

Programa de Patrimônio Cultural Imaterial, o qual insere definitivamente o conceito na ordem do dia, acompanhado de mais duas ocorrências no mesmo ano: o Fundo Fiduciário Japonês/Unesco para a Salvaguarda e Promoção do Patrimônio Cultural Imaterial e a Convenção das Nações Unidas sobre a Diversidade Biológica. ( AIKAWA, 2004)

Retornando à Convenção de Paris e às determinações contidas no documento daí resultante, observa-se que foram necessárias três décadas decorrerem, do documento marco da cultura imaterial, da década de 1970, até que, por fim, em abril de 2006 os termos do dito evento fossem definitivamente efetivados. (AMESCUA, 2013)

$\mathrm{Na}$ corrente desses acontecimentos, o Marabaixo $^{2}$, manifestação artística tipicamente afro-amapaense, certamente se inscreve no rol dos patrimônios culturais imateriais ocupando espaço de destaque no Estado do Amapá por se constatar ultimamente muitos posicionamentos em sua defesa como marca representativa da cultura local.

E é diante da importância da cultura marabaixeira para o e no Amapá que este artigo foi escrito objetivando possibilitar o conhecimento dessa forma de expressão popular e tecer breves comentários sobre as condições de seu reconhecimento em caráter nacional e a existência ou não de política cultural no Estado com destinação de fomento para garantir sua produção, reprodução e longevidade.

\section{MARABAIXO: PATRIMÔNIO CULTURAL IMATERIAL AFRO-AMAPAENSE}

Em março de 2016, durante reunião no Ministério da Cultura (MinC) entre o à época Ministro Juca Ferreira e equipe de pessoal vinculado ao desenvolvimento e fomento de cultura no Estado do Amapá, contando com a presença de Jurema Machado, presidente do Iphan naquela altura, divulgou-se notícia ${ }^{3}$ na qual se informou a proximidade do reconhecimento do Marabaixo como Patrimônio Cultural Imaterial, para compor cenário com outros que já gozavam do status de PCI do norte do Brasil

2 A etimologia da palavra "é incerta: alguns afirmam que vem do árabe marabut (louvar); outros afirmam que vem do fato dos escravos (sic) serem trazidos mar abaixo nos navios negreiros (ou seja, da África para o Brasil).” Disponível em: <https://www.diariodoamapa.com.br/blogs-e-colunas/blogdo-heraldo/conheca-o-que-e-o-marabaixo/>. Acessado em: 07 maio 2020.

3 Ver notícia disponível em: <http://g1.globo.com/ap/amapa/noticia/2015/06/marabaixo-pode-setornar-patrimonio-cultural-e-imaterial-do-pais-diz-ministro.html >. Acessado em: 07 maio 2020. 
como a Roda de Capoeira, do Estado do Acre; a Arte Kusiwa e a Arte Gráfica Wajãpi, do Estado do Amapá; o Círio de Nazaré, do Estado do Pará.

No ano seguinte, notícia disponível no sítio do Iphan (2017, on-line) comentava a ação da Superintendência do Órgão no Estado, a qual, naquele momento, dedicava-se ao "acompanhamento do pedido de Registro do Marabaixo que atualmente está em processo de instrução no Departamento do Patrimônio Imaterial-DPI”, isto é, nesse ano, encontrava-se aquela manifestação cultural em processo de avaliação, não havendo sido atualizado o andamento do processo ao longo do mesmo pelo que se pôde apurar em consulta ao sítio tanto do Iphan quanto do MinC, ou em páginas cujo propósito seja divulgação de notícias de circulação geral, como o Portal G1, e de conteúdo especializado a respeito do que se tem produzido em termos de cultura e política cultural no país.

Em agosto de 2018, o MinC, associado ao Iphan, divulga Dossiê de Registro (BRASIL, 2018), contendo estudo detalhado da manifestação cultural que é o Marabaixo a fim de apresentar elementos teóricos oficiais e fortalecer o processo de seu reconhecimento como PCI, visto que três pedidos já haviam sido encaminhados ao Iphan, até o ano de 2015, pleiteando o seu referido reconhecimento sem, no entanto, alcançarem o objetivo por não conterem essas outras solicitações "devido embasamento documental" (IPHAN, 2018, p. 2).

Ademais, o Parecer do Relator do Conselho Consultivo do Patrimônio Cultural para o Iphan, José Reginaldo Santos Gonçalves, Professor Titular de Antropologia Cultural da Universidade Federal do Rio de Janeiro (UFRJ), não apenas se manifestou favorável "à proposta de inscrição do Marabaixo no Livro de Registro das Formas de Expressão, como Patrimônio Cultural do Brasil, conforme prevê o art. 10, III, do Decreto 3.551/2000" (IPHAN, 2018, p. 13, destaque nosso), como ressaltou a importância desse registro para se combater uma segunda expulsão dos marabaixeiros dos bairros do Laguinho e Favela (Santa Rita) em curso e motivada dessa vez não somente pela segregação étnico-racial, mas também pela especulação imobiliária, além de pretender "fomentar políticas de valorização de espaços e edificações que são condição sine qua non para sua reprodução" (IPHAN, 2018, p. 10, itálicos do autor). 
Decorridos os trâmites legais, em novembro de 2018 o Marabaixo teve seu registro deferido e sua inscrição garantida entre os PCI do Brasil, ao lado de dezessete ${ }^{4}$ outras manifestações culturais oriundas de todas as regiões do país, categorizadas no Livro das Formas de Expressão, sendo importante destacar que a maioria dos PCIs registrados nesse grupo até o momento tem raízes nas culturas indígena (Arte Kusiwa Pintura Corporal e Arte Gráfica Wajãpi, Carimbó, Rtixòkò: Expressão Artística e Cosmológica do Povo Karajá) ou afro-brasileira (Caboclinho, Jongo no Sudeste, Maracatu Nação, Matrizes do Samba do Rio de Janeiro: Partido Alto, Samba de Terreiro e Samba-Enredo, Roda de Capoeira, Samba de Roda do Recôncavo Baiano, Tambor de Crioula do Maranhão).

Contudo, diante dessa descrição, importa indagar, inicialmente, o que, de fato, poderia qualificar o Marabaixo, percebida e praticada expressão artística amapaense, como PCI? Para em seguida ser possível o rastreio de indícios necessários de onde esse processo teve início.

A resposta ao primeiro questionamento toca diretamente na própria definição do conceito a partir do marco legal que lhe configurou as diretrizes, ou seja, a Convenção de 2003, que, no texto do documento, em seu Artigo 2, ao tratar das Definições de PCI, pode-se ler:

Para os objetivos desta Convenção,

1. O "patrimônio cultural imaterial" refer-se às práticas, representações, expressões, conhecimento, habilidades - bem como instrumentos, objetos, artefatos, e espaços culturais a estes associados - aquelas comunidades, grupos e, em alguns casos, indivíduos reconhecidos como parte de seu patrimônio cultural. Este patrimônio cultural imaterial, transmitido de geração em geração, é constantemente recriado por comunidades e grupos em resposta ao seu ambiente e suas interações com a natureza e sua história, proporcionando-lhes um sentimento de identidade e continuidade, e promovendo respeito pela diversidade cultural e criatividade humana. Para os propósitos desta Convenção, serão dadas considerações somente para o patrimônio cultural imaterial que esteja em consonância com os instrumentos dos direitos humanos internacionais,

4 A relação completa dos PCI brasileiros listados como Formas de Expressão encontra-se no sítio do Iphan, disponível em:〈http://portal.iphan.gov.br/pagina/detalhes/497>. Cabe esclarecer que o Iphan mantém na categoria Bens Registrados como Patrimônios Imateriais, disponível em: <http://portal.iphan.gov.br/pagina/detalhes/122>, quatro livros de registro: dos Saberes, das Celebrações, das Formas de Expressão, dos Lugares. 
Disponível em: www.revistafenix.pro.br

bem como com os requerimentos do respeito mútuo entre comunidades, grupos e indivíduos, e do desenvolvimento sustentável.

2. O "patrimônio cultural imaterial", como definido no parágrafo 1 acima, manifesta-se, entre outros, nos seguintes domínios:

(a) tradições orais e expressões, incluindo a linguagem como um veículo do patrimônio cultural imaterial;

(b) artes performáticas;

(c) práticas sociais, rituais e festividades;

(d) conhecimento e práticas referentes à natureza e ao universo;

(e) artesanato tradicional. (UNESCO, 2003, p. 2)

Nota-se não apenas um avanço no texto acima em relação às definições de cultura como no entendimento sobre outras modalidades desta para além daquela cuja forma de representação é o material, havendo, segundo Lima (2014, pp. 11-12), “a identificação das manifestações culturais como marcas de uma temporalidade específica, ressaltando a complexidade e a dinâmica que caracterizam os bens culturais de natureza imaterial", os quais são dispostos em quatro categorias através do Decreto n. 3.551/2000, antecipando, portanto, o dito no Artigo 2 da Convenção de 2003, na seguinte redação:

Art. $1^{\circ}$ Fica instituído o Registro de Bens Culturais de Natureza Imaterial que constituem patrimônio cultural brasileiro.

$\S 1^{\circ}$ Esse registro se fará em um dos seguintes livros:

I - Livro de Registro dos Saberes, onde serão inscritos conhecimentos e modos de fazer enraizados no cotidiano das comunidades;

II - Livro de Registro das Celebrações, onde serão inscritos rituais e festas que marcam a vivência coletiva do trabalho, da religiosidade, do entretenimento e de outras práticas da vida social;

III - Livro de Registro das Formas de Expressão, onde serão inscritas manifestações literárias, musicais, plásticas, cênicas e lúdicas;

IV - Livro de Registro dos Lugares, onde serão inscritos mercados, feiras, santuários, praças e demais espaços onde se concentram e reproduzem práticas culturais coletivas. (BRASIL, 2008, p. 119)

Em cada uma dessas categorias são elencados saberes, práticas, rituais, danças, jogos, expressões musicais e linguagens características de cada cultura e de cada povo 
no território nacional. Acrescente-se, para dar embasamento ao decreto supracitado, que a Constituição Federal de 1988 já apresentava percepção e entendimento do que poderia ser denominado de patrimônio cultural, assim expressando:

Art. 216. Constituem patrimônio cultural brasileiro os bens de natureza material e imaterial, tomados individualmente ou em conjunto, portadores de referência à identidade, à ação, à memória dos diferentes grupos formadores da sociedade brasileira, nos quais se incluem:

I - as formas de expressão;

II - os modos de criar, fazer e viver;

III - as criações científicas, artísticas e tecnológicas;

IV - as obras, objetos, documentos, edificações e demais espaços destinados às manifestações artístico-culturais;

V - os conjuntos urbanos e sítios de valor histórico, paisagístico, artístico, arqueológico, paleontológico, ecológico e científico.

$\S 1^{\circ}$ O Poder Público, com a colaboração da comunidade, promoverá e protegerá o patrimônio cultural brasileiro, por meio de inventários, registros, vigilância, tombamento e desapropriação, e de outras formas de acautelamento e preservação. (BRASIL, 2019, pp. 170-171)

Torna-se evidente pela leitura do texto constitucional a consciência dos legisladores expressa no citado artigo quanto ao que se identificaria no país como patrimônio cultural, seja material, seja imaterial, em consonância com as discussões mais atuais à época da aprovação da Carta de direitos, portanto, podendo-se inferir que estavam os parlamentares da Constituinte inteirados do assunto que se iniciou na década anterior com a Convenção da Unesco, de 1972, e antecipando o uso do termo imaterial, que, conforme apurado, somente teve seu uso inserido no vocabulário das discussões culturais e envolvendo o reconhecimento de patrimônios culturais a partir do Decreto n. 3.551/2000 e ainda mais após a Convenção de Paris.

Essa é uma linha de pensamento igualmente comentada e defendida por alguns autores como Cavalcanti e Fonseca os quais acrescentam que no país pode-se identificar uma dupla motivação para o desenvolvimento do conceito de PCI ao dizerem que:

De um lado, liga-se às preocupações expressas desde os anos 1920 pelo Modernismo brasileiro. Essas preocupações embasam diversas realizações não só intelectuais como institucionais, destacando-se 
entre elas a criação do Serviço do Patrimônio Histórico e Artístico Nacional (SPHAN), em 1937. De outro lado, encontram-se os estímulos provenientes da rede internacional articulada na UNESCO, que, desde seu surgimento, após a Segunda Guerra Mundial, notabiliza-se pela defesa da riqueza humana resultante da diversidade cultural. (CAVALCANTI; FONSECA, 2008, p. 13)

É nesse quadro de preocupação com os elementos culturais da humanidade que marca uma agenda particular no século XX, segundo evidenciou-se pela referência a convenções e à legislação dedicada ao tema, que diversos patrimônios irão requerer atenção a fim de se garantirem seu processo de longevidade cultural e seu reconhecimento como tal.

Nessa trilha de considerações e em seguimento aos aspectos que qualificariam o Marabaixo como PCI é que Videira, em trabalhos discutindo o tema (2005), vem detalhando essa manifestação cultural, contribuindo para sua divulgação e motivando seu conhecimento.

Para tanto, diz a autora:

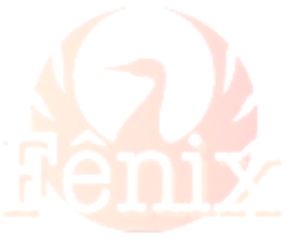

O Marabaixo é uma tradição afroamapaense festivo/religiosa que une ciclos geracionais num período anual chamado de Ciclo do Marabaixo, que acontece logo após os festejos religiosos da Quaresma e Semana Santa dentro da religião católica. (...)

$\mathrm{O}$ ritmo da dança é marcado pelas cantigas entoadas pela cantadeira e ou cantador que formam um conjunto de versos de nome ladrão. $\mathrm{O}$ verso ladrão é retirado de improviso, é rimado e tem o intuito de satirizar, exaltar, criticar e elogiar pessoas e fatos ocorridos no cotidiano local, nacional e mundial. (...) Os instrumentos de percussão que ditam o ritmo da dança recebem a denominação de caixa, que é uma variação do instrumento rústico de nome bombo, oriundo da África Meridional que inscreve o Marabaixo como artefato da cultura de origem Banto de África recriada no Amapá. (...) Os homens predominam na arte de tocar as caixas, mas já temos algumas mulheres quebrando essa hegemonia. O traje característico do Marabaixo é formado pela anágua, saia estampada, arranjo de flores de um lado da cabeça, blusa com folho, toalha sobre os ombros, adornos como: colares, argolas e pulseiras de cores variadas. (VIDEIRA, 2014, pp. 19-20)

A respeito de um dos traços mais característicos do Marabaixo, sua parte cantada denominada de ladrões, é o Dossiê com estudo e detalhes a trazer elementos para aqueles possam ser apropriadamente entendidos. E ao se seguir esse texto, tem-se que: 
Fênix - Revista de História e Estudos Culturais

Janeiro -Junho de 2020 Vol.17 Ano XVII no 1 ISSN: $1807-6971$

Disponível em: www.revistafenix.pro.br

Os ladrões correspondem à música do Marabaixo. Podem ser compreendidos enquanto textos poéticos elaborados de improviso por meio da oralidade. São versos que expressam os acontecimentos corriqueiros ou extraordinários do cotidiano sejam eles vivenciados em âmbito pessoal ou comunitário. Constituem uma forma de registro dos acontecimentos. Seus versos possuem a capacidade de nos transportar para o lugar e o tempo em que foram compostos ou "tirados", na linguagem dos detentores. (BRASIL, 2018, p. 16, itálico no documento)

O que dá a entender esse "tirados" como, nos momentos próprios de desafio que eram as festividades, um desafiante "roubando" uma ideia, um motivo, um dizer, um verso da boca do oponente e fazendo uso disso para compor sua própria cantiga, adquirindo o roubo um sentido metafórico fundamental dessa arte poética oral que é o ladrão, único nesse sentido, mas que encontra eco ou equiparação em outras formas poéticas orais bastante conhecidas no Brasil como o repente.

Disto é possível afirmar que o Marabaixo é uma manifestação cultural ancorada em, pelo menos, três aspectos distintos, complexos e em intercomunicação: o canto, ou cantigas, incorporados na forma de ladrões; a música, "a partir dos toques das caixas, instrumentos de percussão produzidos pelos próprios tocadores" (BRASIL, 2018, p. 6, itálico no documento); e a dança, em que as marabaixeiras realizam movimentos cadenciados de quadril ou podem "seguir ritmos frenéticos, com direito a pequenos saltos e criações coreográficas" (BRASIL, 2018, p. 34), executando-se esses movimentos ao som das caixas e do canto dos ladrões, em círculo e em sentido antihorário.

Como reforçam Benedict (1972), Vannucchi (2006) e Laraia (2007), cultura é toda produção realizada por seres humanos cujas trajetórias históricas e sociais indicam seus lugares de pertencimento, sua compreensão de mundo, suas formas particulares de existência, afastando-se da impetuosidade imperante no mundo natural e, por isso, conteúdos e objetos de cultura se configuram não apenas como aquilo que se produz e que se pode manusear, mas também como memórias e discursos produzidos por grupos ou indivíduos a fim de fortalecerem suas identidades, sendo, por isso mesmo, a cultura a lente através da qual cada sociedade se vê a si mesma e parte daí para tentar compreender as demais em suas diferenças e particularidades.

E o Marabaixo, no Amapá, é uma dessas lentes por meio da qual não apenas indivíduos buscam se definir como também concorrem para a convivência coletiva, participando distinta e dinamicamente no processo de produção e consolidação cultural 
do meio em que vivem, de que maneira pretendem desenvolver suas consciências e produzir um discurso de identidade que os caracterize como sociedade humana.

No tocante ao segundo questionamento disposto no início da seção, cabe ter em mente o fato de que ele se inicia, no contexto nacional, como política do Estado brasileiro, por meio do Decreto n. 25, de 30 de novembro de 1937, da criação do Serviço do Patrimônio Histórico e Artístico Nacional (SPHAN) neste mesmo ano e daí migra gradualmente para contextos regionais e locais, a partir dos anos 2000, tendo-se, em 2005, o lançamento, através do Iphan, do Programa Nacional de Patrimônio Imaterial (PNPI), "tal proposta institucional marcou a superação da antiga idéia de patrimônio cultural demasiadamente focada na sacralização da memória em pedra e cal.” (SILVA, 2011, p. 4)

No Estado do Amapá, especificamente, a discussão sobre o reconhecimento do Marabaixo como PCI ganha corpo a partir de 2015, por proposição de parlamentar representando o Estado na Câmara Federal; esse momento marcou um percurso que somente veio a ter seu ciclo encerrado em novembro de 2018, quando do reconhecimento do Marabaixo como PCI, ponto a que se já se forneceu base explicadora, mesmo a despeito de, ao contrário do que vem sendo praticado pelo Governo Federal, com o PNPI, não haver no Estado ${ }^{5}$ efetivamente plano ou programa destinado a fomentar ${ }^{6}$ qualquer modalidade de cultura.

O que se tem são iniciativas isoladas de parlamentares, de gestores públicos ou de membros da sociedade civil amapaense fazendo proposições documentais, como se deu no caso do parlamentar no evento de 2015, ou visando a solidificação de algumas das categorias de cultura tanto material quanto imaterial para que não sejam completamente ignoradas do público, mas nada que efetivamente se constitua como política cultural do Estado do Amapá, portanto, fato que tem dificultado e dificultou

5 Apesar de o livro de Cavalcanti e Fonseca datar do ano de 2008, constata-se pela consulta ao sumário que àquela altura os únicos estados a conter legislação própria tratando de dar amparo à questão do seu patrimônio cultural eram: Acre, Alagoas, Bahia, Ceará, Distrito Federal, Espírito Santo, Maranhão, Minas Gerais, Paraíba, Pernambuco, Piauí, Santa Catarina, não havendo qualquer menção à legislação nesse quesito existente no Amapá.

6 Há Cartilha do Iphan contendo tópico o qual esclarece que o Governo Federal pensa fomento "de diferentes formas: repassando informações e conhecimento, sugerindo a busca de novos parceiros, auxiliando na divulgação de informações sobre bens culturais, entre outras", principalmente em se tratando de um Estado democrático de direito que deve institucional e socialmente estimular o debate dessas questões. Ver: IPHAN, 2012. p. 31. Disponível em: <http://portal.iphan.gov.br/uploads/publicacao/cartilha_1_parasabermais_web.pdf $>$. Acessado em: 09 maio 2020. 
questões como a do próprio Marabaixo de se tornar $\mathrm{PCI}^{7}$ regulamentado e tombado com devido registro no Iphan, seguindo-se o protocolo demandado pelo órgão, visto que em muitas ocasiões é o cidadão brasileiro, ou nortista, ou amapaense, tendo-se em mente o caso a que se deu evidência, quem assume para si tarefa, responsabilidade e prerrogativa que, ao menos em princípio e por fundamento legal, cabe ao Poder Público, conforme o próprio Decreto n. 3.551/2000 preconiza de maneira hierarquizante, definindo competências, prazos e a quem cabe o cumprimento de cada etapa do processo de registro dos Bens Culturais de Natureza Imaterial:
Art. $2^{\circ}$ São partes legítimas para provocar a instauração do processo de registro:
I - o Ministro de Estado da Cultura;
II - instituições vinculadas ao Ministério da Cultura;
III - Secretarias de Estado, de Município e do Distrito Federal;
IV - sociedades ou associações civis. (BRASIL, 2008, p. 119)

Isso não significa que a sociedade civil deva se isentar desse processo, mas há uma fragmentação de competências que em vez de soar agradável cria obstáculos ao devido andamento de determinados procedimentos, pois o conhecimento técnico, ao menos em teoria competência do gestor público, esbarra na boa fé do cidadão que pretende ter sua identidade cultural valorizada, mas desconhece os caminhos para tal ou está marcado por perspectivas alienantes e preconceitos enraizados, além de, por vezes, alimentar visões de como as deveriam ser e não de como são na cotidianidade, visto haver uma distância considerável e que necessita ser percebida entre as idealidades e a realidade.

\section{CONSIDERAÇÕES FINAIS}

A linguagem e os rumos da política cultural no país avançaram de maneira vigorosa desde a década de 1930 até os dias de hoje, com marcos significativos contidos na Carta de direitos de 1988 e no Decreto n. 3.551/2000, os quais acompanham de perto

\footnotetext{
7 Atente-se para a fala do Relator Consultivo para o Iphan, referenciada na nota 14, supra, sobre as duas tentativas infrutíferas e sem embasamento teórico consistente de reconhecer o Marabaixo como PCI.
} 
na linguagem e nas recomendações o que se passa no restante do mundo e isso pode fazer pensar ser o Brasil um país que respira e transpira cultura de todas as formas, mas este, de fato, ainda não é o caso.

Se houve avanços, por um lado, há, por outro, um desinteresse comprovado de acordo com Machado (Apud SIMIS, 2007, p. 134) “por políticos em geral e cientistas sociais às políticas públicas da área cultural, sejam elas oriundas de órgão federais, estaduais ou municipais". E tudo indica que esse desinteresse não é novidade, não é recente e não é localizado, estendendo-se indistintamente da sociedade civil ao gestor público e de volta.

Uma questão a se pôr sobre o papel do Estado democrático de direito que é este do Brasil, nesse quesito, é a da garantia do direito do cidadão à cultura bem como a devida formulação de políticas públicas na área da cultura a fim de disponibilizá-la ao maior número de pessoas, se possível a todos, já que essa é a aspiração do próprio texto constitucional, contribuindo para sua publicização e, é claro, “fomentando-a, como também políticas de cultura que possam prover meios de produzi-la, pois a democracia pressupõe que o cidadão possa expressar sua visão de mundo em todos os sentidos”, evidentemente, respeitando-se as regras do regime democrático (SIMIS, 2007, p. 135).

Trilhar esse caminho inevitavelmente permitirá a cada brasileiro de qualquer região do país enxergar-se como parte de um contexto multicultural, sendo, por isso, fundamental contribuir-se para a desconstrução de pensamento ainda persistente nesses tempos de que a cultura do "outro" é sentida e, em alguns casos, abraçada como melhor e superior em comparação com a do "eu", sentida e percebida como atrasada ou inferior e, portanto, podendo e devendo ser substituída.

Desse expediente, relatos e ocorrências em diversas sociedades de diversos países têm dado mostras do quão prejudicial tal movimento é para o contato entre sociedades por sustentar a dicotomia avanço-atraso/superior-inferior como aspecto característico de perspectivas consideradas hegemônicas em termos culturais ${ }^{8}$ e por permitir a supressão de traços ou elementos extremamente importantes para a manutenção e conservação de algumas manifestações culturais com menor visibilidade ou pouca representatividade no cenário nacional, retidas e restritas, muitas vezes, às barreiras de seus espaços de realização ou de existência própria.

8 Hegemonia cultural é tomado e utilizado aqui no sentido gramsciano do termo. Recomenda-se, para tanto, os apontamentos de LEARS, 1985. 
Por isso, este artigo, ao trazer para a discussão em política cultural o Marabaixo, manifestação e expressão cultural tipicamente afro-amapaense, tecendo considerações, ainda que breves, sobre sua configuração estrutural, a particularidade de seus elementos constitutivos e o andamento do seu processo de reconhecimento como PCI, até novembro de 2018, pretendeu não fechar avaliação dos pontos expostos, pois são problema contemporâneo, problema deste tempo cuja produção de conteúdo a respeito está em alta, evitando-se a fração modista que escreve apenas para saciar interesses de sujeitos em vez de se pôr para apreciação daqueles a quem mais interessa: o cidadão isolado geograficamente, mas não à força, nesta ponta do norte, às vezes isolado mais ideologicamente que espacialmente, cujo rosto não se dá à exposição, é brasileiro, mas visto e se vendo como menor porque distante, em sua mentalidade, do(s) centro(s) produtor de cultura.

Se se tomar como perspectiva a maneira como indivíduos de uma determinada região do país mesquinhamente veem outros, esse(s) centro(s), desnudado(s) em seu existir, produz(em) cultura, contudo, permeada por vestígios de colonização, de um pensar colonizado que soltou as mãos do grilhão, porém está preso pelo pescoço, vendo por uma lente embaçada, para fazer uso da expressão de Benedict (1972), em metáfora sobre as limitações do olhar.

Se essas reflexões que falam de cultura, de identidade, de patrimônio, de materialidade e imaterialidade e substancialmente de reconhecimento são movimentos do hoje como pro-jeto para o amanhã, para um futuro que se avizinha e espreita, sejam elas propostas como desafios a serem superados, em linguagem a ser desvendada para aqueles ainda por vir poderem firmar compromisso com o hoje deles, o nosso amanhã e o ontem de outros em um ciclo constante e dinâmico envolto de representações ${ }^{9}$ às quais o humano dá sentido por saber e sentir que pertence a algum lugar, que tem raízes e um rosto no qual se expressa cada uma e todas as partes de que é composta sua personalidade, como sujeito fazedor de cultura, composto, múltiplo, mas sem abandonar a unidade que lhe dá razão de ser e existir.

9 O filósofo alemão destaca uma nova dimensão específica do homem que é o "sistema simbólico" composto por todas as realizações subjetivas engendradas por aquele e do qual fazem parte a linguagem, as narrativas (mitologias), as diversas expressões artísticas, a religião e, entrelaçando todas, a cultura. (CASSIRER, , 2012. p. 47-48) 


\section{REFERÊNCIAS BIBLIOGRÁFICAS}

AIKAWA, Noriko. An historical overview of the preparation of the UNESCO international Convention for the Safeguarding of the Intangible Cultural Heritage. Museum. No. 221-222 (Vol. 56. No. 1-2, p. 137-149, 2004.

AMESCUA, Cristina. Anthropology of Intangible Cultural Heritage and Migration: an uncharted field. In: ARIZPE, Lourdes; AMESCUA, Cristina (Eds.). Anthropological perspectives on Intangible Cultural Heritage. New York: Springer, 2013. p. 103-120. BENEDICT, Ruth. O crisântemo e a espada: padrões da cultura japonesa. São Paulo: Editora Perspectiva, 1972.

BRASIL. Decreto $\mathrm{n}^{\mathrm{o}}$ 3.551, de 4 de agosto de 2000. In: CAVALCANTI, Maria Laura Viveiros de Castro; FONSECA, Maria Cecília Londres. Patrimônio imaterial no Brasil: legislação e políticas estaduais. Brasília: UNESCO, Educarte, 2008. p. 119-120.

Ministério da Cultura. Instituto do Patrimônio Histórico e Artístico Nacional. Dossiê de registro: Marabaixo. Brasília/DF, agosto, 2018. Disponível em: <http://portal.iphan.gov.br/uploads/ckfinder/arquivos/DOSSIE_MARABAIXO.pdf>.

Acessado em 07 maio 2020.

Constituição da República Federativa do Brasil. Brasília: Supremo Tribunal Federal, Secretaria de Documentação, 2019.

CABRAL, Clara Maria Ferreira Bertrand. Património cultural imaterial: proposta de uma metodologia de inventariação. Dissertação (Mestrado em Ciências Antropológicas). Instituto Superior de Ciências Sociais e Políticas de Lisboa. Universidade Técnicas de Lisboa, 2009.

CARVALHO, Ana Filipa Estêvão de. Reafirmar a identidade cultural local: património cultural imaterial local como recurso. Dissertação (Mestre em Educação Social e Intervenção Comunitária). Instituto Politécnico de Lisboa. Escola Superior de Lisboa, 2014.

CASSIRER, Ernst. Ensaio sobre o homem: introdução a uma filosofia da cultura humana. São Paulo: Martins Fontes, 2012.

CAVALCANTI, Maria Laura Viveiros de Castro; FONSECA, Maria Cecília Londres. Antecedentes históricos. In: Patrimônio imaterial no Brasil: legislação e políticas estaduais. Brasília: UNESCO, Educarte, 2008. p. 13-17.

CORÁ, Maria Amelia Jundurian. Do material ao imaterial: patrimônios culturais do Brasil. Tese (Doutorado em Ciências Sociais). Pontifícia Universidade Católica de São Paulo, 2011.

COSTA, Rodrigo Vieira. O registro do patrimônio cultural imaterial como mecanismo de reconhecimento de direitos intelectuais coletivos de povos e comunidades tradicionais: os efeitos do instrumento sob a ótica dos direitos culturais. Tese (Doutorado em Direito). Universidade Federal de Santa Catarina, Centro de Ciências Jurídicas. Florianópolis, 2017.

IPHAN. Programa Nacional do Patrimônio Imaterial: balanços e perspectivas. Notícia on-line, 10 de agosto de 2017. Disponível em: <http://portal.iphan.gov.br/noticias/detalhes/4257>. Acessado em: 07 maio 2020.

IPHAN. Instituto do Patrimônio Histórico e Artístico Nacional. Os sambas, as rodas, os bumbas, os meus e os bois: princípios, ações e resultados da política de salvaguarda do patrimônio cultural imaterial do Brasil (2003-2010). Brasília/DF, Ministério da Cultura, 2010. 
IPHAN, INSTITUTO DO PATRIMÔNIO HISTÓRICO E ARTÍSTICO NACIONAL. Patrimônio Cultural Imaterial: para saber mais. 3. ed. Brasília, DF: Iphan, 2012. p. 31.

Disponível

em:

<http://portal.iphan.gov.br/uploads/publicacao/cartilha_1_parasabermais_web.pdf $>$.

Acessado em: 09 maio 2020.

Parecer do Relator do Conselho Consultivo do Patrimônio Cultural Professor Dr. José Reginaldo Santos Gonçalves (UFRJ). 08 de novembro de 2018. Disponível em: 〈http://portal.iphan.gov.br/uploads/ckfinder/arquivos/Marabaixo.pdf>. Acessado em: 07 maio 2020.

LARAIA, Roque de Barros. Cultura: um conceito antropológico. 21. ed. Rio de Janeiro: Jorge Zahar Ed., 2007.

LEARS, T. J. Jackson. The concept of cultural hegemony: problems and possibilities. The American Historical Review, Vol. 90, No. 3, p. 567-593, jun., 1985.

LIMA, Alessandra Rodrigues. $O$ reconhecimento do patrimônio cultural afrobrasileiro. Revista Palmares, Cultura Afro-brasileira, Ano X, p. 6-15, Edição 08 novembro 2014.

PELEGRINI, Sandra C. A.; FUNARI, Pedro Paulo. O que é patrimônio cultural imaterial. São Paulo: Editora Brasiliense, 2008.

SILVA, Paulo Sérgio da. Patrimônio cultural imaterial: conceito e instrumentos legais de tutela na atual ordem jurídica brasileira. Anais do XXVI Simpósio Nacional de História - ANPUH, São Paulo, p. 1-11, julho de 2011. Disponível em: <http://www.snh2011.anpuh.org/resources/anais/14/1312573747_ARQUIVO_Patrimon io_cultural imaterial.pdf >. Acessado em: 09 maio 2020.

SIMIS, Anita. A política cultura como política pública. In: RUBIM, Antonio Albino Canelas; BARBALHO, Alexandre (Orgs.). Políticas culturais no Brasil. Rubim, Salvador: EDUFBA, 2007. p. 133-155.

UNESCO. Convention for the Safeguarding of the Intangible Cultural Heritage. Paris, $17 \quad$ October, 2003. Disponível em: <https://unesdoc.unesco.org/ark:/48223/pf0000132540>. Acessado em: 08 maio 2020.

VANNUCCHI, Aldo. Cultura brasileira. São Paulo: Edições Loyola, 2006.

VÁZQUEZ, Adolfo Sánchez. Filosofía de la praxis. Ciudad de Mexico: Siglo Veintiuno Editores, 2003

VIDEIRA, Piedade Lino. O Marabaixo do Amapá: encontros de saberes, histórias e memórias afro-amapaenses. Revista Palmares, Cultura Afro-brasileira, Ano X, p. 1621, Edição 08 - novembro 2014, p. 19-20. 